\title{
11 Hip-hop and racial identification: an (auto)ethnographic perspective
}

\author{
ANTHONY KWAME HARRISON
}

\section{Introduction: the arrival story}

My first time attending the Day One DJs' hip-hop open microphone at Haight Street's (San Francisco) Rockin' Java Café, I was fortunate to see one familiar face: underground rapper Murs, who, at the time, was most popularly associated with the Living Legends collective. Since that chance meeting over a decade ago, Murs's career has blossomed through a series of critically heralded releases and collaborations with artists including 9th Wonder, Slug (of Atmosphere), will.i.am, and Snoop Dogg. Yet even at this early stage in his career, within the interior spaces of Bay Area underground hip-hop open mics, Murs's presence was a big and noticeable deal. Had I spotted him first, I imagine I would have been hesitant to approach him: conventions of subcultural posturing dictate that one does not unnecessarily crowd local celebrities. Fortunately, he saw me and immediately came over, greeting me with a handclasp and a hug, and the question, "What are you doing here?"

I had arrived in California three weeks earlier to begin a year-long ethnographic research project within the San Francisco Bay area's multiracial underground hip-hop scene. ${ }^{1}$ Ethnography is a specific form of qualitative research methodology based on long-term participant observation within a cultural setting. Ethnographers typically take up residence in a community and seek to understand people's everyday lives by watching what happens, listening to what is said, asking questions, and sometimes joining them in what is going on. ${ }^{2}$

Serendipitously, part of my own ethnographic immersion involved landing a job working two doors down from Rockin' Java at Amoeba Music the then-largest independent record store in America, ${ }^{3}$ and a key hub of the local hip-hop scene. The Day One open mic had been recommended to me by an Amoeba co-worker and thus, even before realizing it was one of the largest and longest-standing weekly hip-hop open-microphone events in the Bay, I anticipated it being an important research site.

I had met Murs once before, in 1998 when the Living Legends embarked on their first-ever national tour as an opening act for fellow Bay Area hip-hoppers Hieroglyphics. Following a canceled show in Albany, the first 
actual performance of the tour took place in Northampton, Massachusetts not far from where I grew up and went to school as an undergraduate. Through a combination of my familiarity with the venue and what I suspect was an instance of racial (mis)recognition, my friend Dustin and I managed to not only get a room in the same motel as the tour, but to get one right in the middle of the Hieroglyphics room block. Since Black men with dreadlocks rarely passed through the "small, liberal-minded, 90 percent white college town," I imagine the clerk took one look at me and assumed I was a late-arriving member of the crew. ${ }^{4}$ I didn't mind the misrecognition. That's what we were there for.

A few hours before the start of the show, the most-renowned member of Hieroglyphics, Del the Funky Homosapien, walked into our room. With the door open and the music turned up, Del most likely mistook ours for a Hiero room. I immediately offered him a beer and a seat. Del ended up spending most of the night - both before and after the show - in our room. Subsequently, a few other Hiero members and most of the Living Legends camped out there as well. Through my regular participation on the Living Legends online forum (the Legends Labyrinth), I had learned that Murs knew and was a fan of a German hip-hop artist named Juks, whom my friend Owa had met the previous summer while visiting Berlin. In anticipation of seeing the Legends for the first time in Northampton, I had brought along a second-generation dub of Juks's underground cassette-tape specifically for Murs, thus reconciling three degrees of transatlantic separation between the two artists. He seemed genuinely thankful to receive it.

Now in San Francisco, possibly as a gesture of reciprocity, Murs was handing me his newly pressed CD, F'Real..$^{5}$ Initially, I assumed he was only showing it to me. "No. That one's for you," he said. ${ }^{6}$ We spoke for a few minutes: he happened to be passing through Rockin' Java on his way to drop off copies of F'Real at Amoeba; I told him about my research and explained how I planned to be in the Bay for the next year; he bemoaned my choice of city, suggesting that Los Angeles - where he and the rest of the Legends had recently relocated - would have been a better fieldwork site; "I know you're having a good time though," he affirmed. Murs stayed for the entire open mic. It was the only time I ever saw him there.

Although Murs did not get on the microphone to perform that evening, as an established artist in the scene - arguably the most celebrated artist I saw at the Rockin' Java - his mere presence involved a performance or, to borrow Erving Goffman's terminology, "presentation-of-his-celebrityself." As a Living Legend - the crew which, according to Amoeba Music's head hip-hop buyer, "all these [Bay Area hip-hop] kids have taken a page from" - with the foremost reputation as a fierce freestyler and battle $\mathrm{MC}$, Murs was the object of aspiring hip-hoppers' clandestine gazes from the 
moment he entered the coffee shop. ${ }^{8}$ And fortuitously for me, those people he showed familiarity with and warmth to were, if nothing else, worth taking note of.

Within popular music scenes, especially those governed by authenticity demands, the identity-work participants perform serves as an (subjective) experience of and (objective) occasion for what Simon Frith describes as "self-in-process." Certainly all hip-hoppers engage in forms of "impression management" while vying for subcultural acceptance, status, and/or validation. ${ }^{10}$ Murs, through the rare occasion of his presence in a pungent music-scene space like the Day One open mic, was involuntarily pressed into a profound performance-of-self. Such is the price of celebrity at any level. A known figure is subject to surveillance upon recognition. At the same time, for a first time attendee at the open mic - an unknown figure the performance-of-self can be similarly consequential. First impressions matter, as the example of Murs's greeting me for only the second time attests. Thus, in that moment of mutual recognition, Murs and I entered into a heightened performance of who's who in the underground hip-hop scene - "There goes Murs! And who's that he's talking to?" His knownness and my unknownness became symbiotic - the valences between the two were pregnant with the potential for misrecognition.

There is yet another valence through which our off-stage performances that evening can and should be recognized. In fact, my own recognition of it in the weeks and months that followed became a jumping-off point for theorizing the implications of social identification within a music scene where it was widely said - and widely known to be said - that a person's race had no direct bearing on the artistic evaluation of their performative prowess (i.e. "it's all about an MC's skills"). This valence, of course, is the "vast veil" of separation and difference that W. E. B. DuBois, in contemplating the Black experience in America, wrote about over a century ago. ${ }^{11}$ That Murs and I were two of only a handful (perhaps a half dozen) of recognizably African American people at the hip-hop open mic undeniably added to my visibility there. Whereas Murs's recognition of me as the person he had met in Northampton made me someone notable, it was through recognition of race - the historically contingent meanings which we inconsistently assign to a constellation of phenotypical signifiers (such as skin color, hair, and facial features) - that I became noticeable.

Over the course of the following year, as I seamlessly made the transition from an at times tentative ethnographer to a central figure in the Day One open microphone "microscene" (i.e. scene within a scene), I would realize how much being recognized as a (particular type of) racial subject, and the performance of race that accompanied such recognition, enabled and accelerated my journey. ${ }^{12}$ I would also become profoundly aware of the extent to 
which a second type of racial recognition - that is, the acknowledgment of specific aesthetic and/or political traditions associated with distinct racial identities - conspired with the first type to betray the colorblind ideals of this multiracial community.

In this chapter I present a snapshot of critically grounded hip-hop ethnography that examines the implications of racial recognition and identification within a purported colorblind underground hip-hop scene. To do this, I focus on a few thickly described autoethnographic episodes which showcase some of the ways in which these racial identifications perform identity-work. ${ }^{13}$ My analysis issues from considerations of how my own racial visibility impacted my early experiences of acceptance as a researcher and, ultimately, an MC. Ethnographic research within hip-hop music scenes offers an important on-the-ground perspective through which to explore the dynamics of power that shape a number of interpersonal encounters and social processes, not the least of which surround race. In the following pages, I develop a theory of racial identification (in underground hip-hop) that is both an outgrowth of my own positioned subjectivity and a guiding framework for what I witnessed among the hip-hoppers I met and interacted with - people who, like me, had to negotiate the terrain of identification, authenticity, and community belonging as part of their everyday movements within the scene. I first offer some preliminary comments on the practice of ethnographic research: its history, what it currently entails, and its place as an emergent mode of hip-hop scholarship.

\section{Ethnography and hip-hop}

Considering the extent to which hip-hop has been represented and discussed - in both the academy and everyday discourse - as a culture, it is surprising that the research methodology traditionally most associated with the study of culture has been utilized so sparingly within the history of hip-hop scholarship. Although ethnography has a long tradition within sociocultural anthropology, cultural sociology, and ethnomusicology, and has more recently been adopted by a broad range of disciplines, within the field of popular music studies its development has been relatively slow. ${ }^{14}$ As a mode of research that came of age during the colonial era, classic ethnography involved traveling to distant cultures, attempting to live alongside and, to the extent feasible (or comfortable), similarly to indigenous peoples, with the goal of "grasp[ing] the native's point of view." 15 Ethnography today is recognized as a distinctly interpersonal research endeavor that is often practiced close to home. ${ }^{16}$ Thus the ethnographer's ability to live identically to community members - and to be (mis)recognized as a member to the point 
where daily life proceeds as if she were not there ${ }^{17}$ - is generally increased and specifically impacted by particulars relating to both her identity and the boundary-maintaining measures of the community she aspires to conduct research within. Ethnographic projects are furthermore influenced by countless arbitrary, idiosyncratic, and unforeseen factors including, but by no means limited to, the personality characteristics of both the researcher and the specific people she encounters, and the circumstances under which she is introduced to the research community - even who happens to show up on her first night attending an open mic.

With these revelations at the fore, contemporary ethnography developed into a highly self-conscious research methodology concerned with both the power relations surrounding ethnographic projects and the politics of ethnographic representation. ${ }^{18}$ At the micro-social level of everyday interactions, such considerations compel ethnographers to be cognizant of what Peter McLaren calls "reception formations" - that is, historically and culturally based understandings of the research enterprise that impact on how an ethnographer is both perceived and received - as well as the constant negotiations of identities taking place throughout the course of research. ${ }^{19}$

Popular music scenes offer uniquely suited sites for ethnographers to productively work through many of these methodological complexities. These decidedly social arenas exist as communities of practice through which the usual designators of collective identity (i.e. race, class, gender, ethnicity, sexuality, and religion) are often secondary to matters of mutual engagement and shared repertoires. ${ }^{20}$ This is not to suggest that race, gender, and (especially) age are not consequential to perceptions of in-scene belonging - indeed one of my principal arguments in this chapter is for the ongoing salience of racial identifications in the face of underground hiphop's professed colorblindness - but rather that (a) joint participation in activities through which subcultural meanings are negotiated, and (b) collectively recognized ways of doing and saying things serve as two key aspects of a music scene's production and maintenance of community. ${ }^{21}$ As a particular type of music around which scenes often form, hip-hop has a robust history of being authenticated around specific discourses of race (Black), gender (male), sexuality (hyper-heterosexual), and class (poor/working class). ${ }^{22}$ The emergence of underground hip-hop - as a multiracial, more socially conscious alternative to commercial rap music, which has strong resonances within middle-class enclaves such as college towns - threatens to unsettle some of these ascriptive historical associations. ${ }^{23}$ Through the virtues of its relationally and contextually situated attentions to the lived experiences of individuals, ethnography, when applied to (underground) hip-hop communities of practice, can help shed light on the dynamic and nuanced relationship between (largely exclusive) ascribed social identities 
and (largely inclusive) engaged communities - a tension that is crucial to the development of healthy and just twenty-first-century societies.

Arising largely out of interests in documenting the textures of hip -hop's global spread, a small canon of hip-hop ethnographies set outside the USA began emerging around the start of the twenty-first century, including studies in northeast England, Berlin, Sydney, Tokyo, and Havana. ${ }^{24}$ More recently there has been an upsurge in USA-based ethnographies on hip-hop - represented most notably through academic books authored by second-generation hip-hop scholars like Joseph Schloss, Ali Colleen Neff, Andreana Clay, and Emery Petchauer. ${ }^{25}$ Collectively, these works seek to legitimate hip-hop's aesthetics and practices through (re)presenting the actions, viewpoints, and voices of hip-hoppers themselves. Rather than relying on pre-established theories or emphasizing large-scale structural shifts that have little to no resonance with people's daily experiences, ethnography is more adept at presenting situational thick descriptions in an explanatory tone. Hip-hop ethnographers, while still drawing on theory and aiming to contextualize broad patterns of behavior, privilege the grounded perspectives of everyday social actors - which are notably distinct from the standpoints of invested celebrity artists or spokespersons. Indeed, the best contemporary ethnographers understand their enterprise as a project of sharing voice. And perhaps not surprisingly, several members of this new generation of hip-hop scholars - including Schloss, Neff, Petchauer, Sujatha Fernandes, Oliver Wang, and Jooyoung Lee-consider (or have at one time considered) themselves scholar-practitioners. ${ }^{26}$ I include myself among these. Yet, the path of welcome that led me to becoming an open-mic performer who was known and recognized in this (micro)scene cuts through a forest of racial recognition and $\mathrm{MC}$ misrecognition, with an understory that illustrates just how much we ask and continue to make of the complex combination of visible attributes we understand as race. ${ }^{27}$

\section{... back at the open mic}

The following week, when I arrived at the Rockin' Java a couple of hours early to enjoy the pre-open microphone music and get caught up on fieldnote writing, three-and-a-half pages into my work I was pleasantly interrupted by one of the stand out MCs from the week before. Lord Top Ramen (aka Top R) was a large, loud, and bodacious freestyle rhymer who dominated just about every open mic or thyming cypher I ever saw him in (and I saw him in many). Although he had family ties back east, within the Bay Area scene Top R was known as a grafftiartist and MC from Santa Cruz who had made a name for himself - or at least a reputation as a big white guy with 
dope rhymes ${ }^{28}$ (see Harrison 2009: 139-140) - through his membership of a group called the Earthlings and by working security at Maritime Hall. Prior to its closing in 2001, Maritime was the largest venue for Black music in San Francisco. As a security person there, Top R seized any and all opportunities to get in front of the crowd and freestyle or battle other MCs both on stage and backstage. Having been in the Bay for less than a month, I knew none of this. What I did know from the previous week was that Top $\mathrm{R}$, a self-designated "mic hog," rhymed longer and more frequently than anyone else, had a commanding presence, and had what in Bay Area underground hip-hop vernacular one might call the "cleanest" rhymes - meaning that, even though he rhymed off the top of his head, he rarely stumbled or messed up. ${ }^{29}$ Indeed, Top R's impromptu performances, which often included witty punchlines, very much resembled written rhymes - a fact his MC adversaries were not above calling him on. ${ }^{30}$

Top $\mathrm{R}$ first approached me asking if $\mathrm{I}$ was writing rhymes. His misrecognition of me as an MC was not the first or the last; in this instance, it provided a convenient opportunity to introduce myself and my research. After listening to me describe my interest in studying the multiracial character of Bay Area underground hip-hop for my doctoral thesis in cultural anthropology, Top R immediately decided to educate me on several historical and contextual aspects of my proposed study. The first regarded the history of African American migration to the Bay Area - most notably around World War II to work in the Oakland shipyards - and how it gave Black music from "the (Oak) Town" a certain "country" sound. ${ }^{31}$ The second concerned hip-hop and cultural appropriation. Whereas many African American scholars have written about the injustices of white appropriations of Black culture, and some have debated the extent to which white hip-hop enthusiasts are simply repeating this historical cycle, being a white hip-hopper himself, Top $\mathrm{R}$ felt obliged to share his views on this controversial issue. ${ }^{32}$ Rather than seeing the Bay Area's tremendous racial/ethnic diversity - which in many ways anticipates mid-twenty-first-century US population projections ${ }^{33}$ - as limiting cultural appropriation or leading to a more genuine form of crosscultural blending, Top $R$ thought the Bay was nationally at "the forefront of the appropriation of Black cultural styles." Furthermore, speaking as a white $\mathrm{MC}$, he stressed the importance of being conscious of his position in hip-hop and aware of how his actions conformed to, disrupted, and/or otherwise engaged this historically exploitative dynamic. A third aspect of Bay Area hip-hop which Top R schooled me on was the local history of activism - namely the Black Panthers and the anti-Vietnam War protests and how it informed the do-it-yourself ethos of hip-hop career-building introduced by Oakland's Too \$hort, continued by artists like Vallejo's Mac Dre and E-40, and, at that time, currently exploding within the hip-hop 
underground through exemplars like the Living Legends and San Francisco's Bored Stiff.

Finally, Top R and I discussed anthropology, most specifically its methodology. When I shared my own misgivings about the politics of ethnographic research and the vagaries of its methodological prescripts, Top R countered that anthropology, indeed, had a definitively purposeful method: "[frst] you immerse yourself and [then you] gain trust." As he went on making less than flattering comments about the history and implications of the research tradition I was participating in - adding a line or two about the pretentiousness of academics in general and graduate students in particular - he made sure to intersperse explicit recognitions of my personhood via statements like "not to diss on you" or "but you're not like that." 34 Through this first conversation with Top R, I (1) learned and/or confirmed many things about Bay Area hip-hop, (2) discovered that his freestlye proficiency could, in part, be attributed to the fact that he was well read and had a sharp mind, and (3) realized that his extroversion was not limited to rhyme cyphers and open microphones. Later that evening, during one of his freestyles on stage, Top R pointed over to me and said, "my man's an anthropologist."

\section{Theorizing race through (mis)recognitions}

Both Top R's misrecognition of me as an MC and his subsequent recognition of me as a person who, perchance in a deliberate gesture to avoid offending, he distanced from the anthropological enterprise as he understood it, offer instructive instances for beginning to think through how the visibility and conception of race and the performance of racialized selves-in-process shape underground hip-hop community-building - not to mention the research encounters of hip-hop ethnographers. To begin, we might simply (but quite significantly) consider how I was fortunate enough to, through no great effort on my part other than simply being there, quickly establish what became a solid (and trusting) relationship with the dominant persona at the Rockin' Java open mic ${ }^{35}$ My experience of ethnographic immersion into this open-microphone-based hip-hop microscene was notably different from Jooyoung Lee's, who, even as a hip-hop practitioner (a tumtablist and popper), recounts that months into research people still periodically reminded him of his "provisional status." 36 The most obvious explanation for my welcome reception is racial. ${ }^{37}$ By this proposition, Top R's initial misrecognition of me was no different from the motel clerk's described in this chapter's introduction. As a perceived African American with a recognizably underground hip-hop look - including dreadlocks, baggy jeans, 
and an Ecko Unltd. messenger bag - what else besides rhymes could I have possibly been writing prior to a hip-hop open mic? ${ }^{38}$

I cannot be certain this was Top R's thought process. However, based on several similar misrecognitions as well as various opportunities and encouragements I received to freestyle and/or record music over the course of the following weeks (see below), it is evident to me that perceptions of my racial identity aligned with norms of identification - i.e. notions of what certain people ought to do and ought not to do - surrounding race and hip-hop. ${ }^{39}$ Despite the colorblind ideals aspired to within the scene, a clear association between recognized/ascribed Blackness and the practice of MCing endured. Yet Top R's misrecognition could have been attributable to a second recognition in addition to race: this would be his recognition of me (from the previous week) as someone Murs knew - and if he was paying close enough attention he would have recognized that Murs knew me well enough to give me a $\mathrm{CD} .{ }^{40} \mathrm{Of}$ course these two possibilities are more complementary than mutually exclusive. And there is always the possibility that he would have made such an inquiry of anyone putting pen to paper prior to an open mic.

The specter of race, as DuBois observed in his famous doubleconsciousness postulation, steadily pursues and perpetually preoccupies those who have its markings involuntarily cast upon them. ${ }^{41}$ This means that the possibility of being treated in a certain way - whether that way is bad, good, or simply distinct - as a result of being recognized as belonging to a certain race is consistently present. This can range from experiences as innocuous as being selected first (or last) in a pick-up basketball game to something as consequential as being racially profiled. Where and when racial identity is unmarked - this would apply mainly to white Americans (or Europeans or Australians) in most ordinary social settings - the idea of being treated in a certain way as a result of one's race tends to only arise under extraordinary circumstances. Of course, within the broad domain of hip-hop (underground and commercial, national and global) whiteness is often marked - thus Top R becomes "a white guy with dope rhymes" (see above). Yet as part of a larger American (or British, German, Australian, etc.) society, non-whiteness is also marked. Consequently, hip-hop scenes become profitable venues for examining the complex structures and negotiations surrounding race.

The relational dynamics of racial identification that $I$ have thus far sketched correspond with Kwame Appiah's perceptive thoughts on the role that identities play in structuring the terms of mutual conduct through which people interact. Appiah's framework, designed to shed light on "important features of the way social identities work," resonates powerfully with both my own experiences as a racially recognized ethnographer and 
the regimes of racial understandings and expectations I observed Bay Area underground hip-hoppers continually negotiating. ${ }^{42}$ Whereas Appiah's model concerns social identities in general, here I am applying it specifically to race.

Appiah develops his thinking around four processes through which identities take on interrelational salience: "ascription," "identification," "treatment," and (the aforementioned) "norms of identification". Ascription refers to the invariably imperfect schemas people develop which enable them, in most instances, to classify persons as either determinately in or determinately not in an identified (in my case racial) group. This is what I have been calling "racial recognition": I am (recognized as) Black, Top $\mathrm{R}$ is (recognized as) white, several MCs at the Rockin' Java open mic are neither Black nor white but are still labeled racially, sometimes as a combination of recognized groups. Appiah's second process, identification, extends ascription's often visually based recognition (of race) to an acknowledged self-recognition that "figures in a certain typical way into [one's] thoughts, feelings and acts." ${ }^{33}$ Importantly, how it figures is not prescribed: the fact that I self-recognize as Black does not mean that (in a hip-hop context) I should $\mathrm{MC}$; and the fact Top R identifies as white and an $\mathrm{MC}$ does not mean that he should avoid or become defensive during discussions of cultural appropriation. What's vital is that my feeling Black, or his feeling white, or another hip-hopper's feeling Latino or Asian American matters in a relevant way that leads us to consciously act from our positions of subjective racial self-recognition. ${ }^{44}$ In chorus with John L. Jackson, I believe that this distinction between restrictive scripts of racial authenticity and (inter-) subjective performances of racial sincerity is critical to understanding the complex and nuanced ways in which race persists as a basis for social solidarity and is lived both "intimately" and "affectively." 45

For Appiah, the differential treatment of people - ranging from "supererogatory kindness" to "opprobrious unkindness" - as a result of their being recognized as belonging to a certain (racial) group becomes a third way in which social-identity labels function. ${ }^{46}$ This process of treatment, of course, in the interactional context of underground hip-hop sociality and/or ethnographic research, can be especially consequential to how these relational performances-of-self play out. Although Appiah (rightfully) acknowledges the degree of latitude surrounding the ways in which modes of identification and treatment shape everyday encounters and life plans, he does not overlook the norms of identification - both self- and collectively imposed regimes of "appropriate" behavior - which work to rein in eccentric excesses and provide common grounding for group membership. This is where the racial recognition of being Black or white or Native American, even in a multiracial underground hip-hop context, gets tethered to 
an insistence that certain additional things are recognized and/or to be expected.

\section{You better recognize}

The occasion of my meeting Top $\mathrm{R}$ and his meeting me - our initial selves-inprocess interactive moment - intimately illustrates a performative dialectic I observed playing out in the situational acts of racialization taking place throughout the Bay Area's underground hip-hop scene. Curiously, our most telling exchange might have had more to do with my identification as an (African American) anthropologist than with his as a (white) hip-hopper. I am alluding to Top R's recognition of my personhood, actualized through the comment "but you're not like that." The "that" to which he referred is an established (if at times embellished) narrative of anthropology's collusion with and complicity in matters of institutional surveillance and colonial domination, which people knowledgeable of the discipline and possessing a critical disposition are well aware of. ${ }^{47}$ I had introduced myself as an anthropologist, but through the combination of Top R's racial recognition of me (as Black) and my performance-of-self in conversation with him-here I would spotlight my confessed misgivings about the politics of research I became "not that kind of anthropologist." Within underground hip-hop circles, this history of anthropology is relatively obscure; yet the narratives surrounding the history and essential qualities of hip-hop, and notably those concerning white participation in hip-hop, are well rehearsed. ${ }^{48}$ Any white hip-hopper journeying outside of exclusively white enclaves has likely been tested and challenged on certain to-be-expected grounds. Through Top R's performance-of-self, he, in so many words, sought to solicit my recognition of him as "not that kind of white hip hopper." Just as I was a part of, but not contained within, an anthropological tradition that included colonial complicities, he became a white MC who acknowledged but was not defined by the history of white participation in Black music. What's significant here is that my deviation from a practiced anthropological tradition was, in part, attributable to my recognized race, whereas Top R's deviation from an ascribed racialized tradition was in spite of his.

Where the terms of subcultural authenticity are well known if not well worn, the most sincere bids to belong involve, first, acknowledging oneself as a particular type of positioned subject in relation to a community of practice - along axes of race, gender, age, (possibly) class, and/or any other type of (usually) visually based identity ascription - and, then, performing one's identity, regardless of the performed content, in dialogue with recognized identity scripts. Through such propositions we not only become 
more aware of the remarkable diversity of subjective positions (i.e. the untethered counterpoints to positioned subjects) contained within ascriptive labels, but also modify existing norms of identification, and better recognize the constructed nature of social identities.

\section{(W)rapping it up}

In terms of my own journey, being recognized as someone Top $\mathrm{R}$ knew and who knew Top $\mathrm{R}$ - would favorably mark my movements within the underground hip-hop scene from that day forward. Through our association, my racial noticeability became notable as well. As summer arrived and the open-mic crowds grew larger, I came to be both a fixture (i.e. object of other people's gazes) and a known person at the Rockin' Java open mic. Three months after meeting Top R, I would take my first steps toward freestyling publicly by joining him in a rhyme cypher one evening in Golden Gate Park. ${ }^{49}$ In the weeks leading up to that night, several open mic regulars had inquired about my reluctance to rhyme on stage and/or encouraged me to "just go up there." When I finally decided to go, my reception was favorable and supportive - especially from those who had been expectantly waiting, but also from several MCs who, over the course of my year in the Bay, happened to pass through the open microphone. I extensively got recognized as an MC at other hip-hop venues around the city and even while walking its streets. Notably, Top R - although genuinely appreciative of my first attempt to rhyme with him in the park - seemed ambivalent toward my continued efforts. Once, following one of my better freestyles, he noted with a tone of indifference that I was "up there rapping" as he turned to look for someone else in the crowd. And years later, after the fruits of these initial rhyming experiences had led to the release of three albums (with two different groups), Murs bluntly asked me what my motivation for rapping was.

The focus of this chapter has been to examine how particular types of racial recognition foster certain kinds of self-in-process identifications in an underground hip-hop context. As the precarious and contingent nature of much of what I have described illustrates, this is nothing if not complicated terrain. A closing note on the racial and relational performances-of-selves I have sought to theorize here concerns the potential for widely recognized norms of identification to become self-fulfilling prophecies. In interactional exchanges such as those outlined above, the demands associated with expected behavior(s) are either realized or not realized through a dialectic between their (subjective) self-recognition as a basis of identification and their (objective) recognition by others as a basis for treatment. In the case of 
the ethnographer mistaken for an emcee, it was this treatment that foremost stimulated the transition from misrecognition to recognition.

\section{Further reading}

Fernandes, Sujatha, Close to the Edge: In Search of the Global Hip Hop Generation

(New York: Verso, 2011).

Harrison, Anthony Kwame, Hip Hop Underground: The Integrity and Ethics of Racial Identification (Philadelphia: Temple University Press, 2009).

Jackson, John L., Jr., Real Black: Adventures of Racial Sincerity (University of Chicago Press, 2005).

Jeffries, Michael P., Thug Life: Race, Gender, and the Meaning of Hip Hop (University of Chicago Press, 2011).

Morgan, Marcyliena, The Real Hiphop: Battling for Knowledge, Power, and Respect in the LA Underground (Durham, NC: Duke University Press, 2009).

Neff, Ali Colleen, Let the World Listen Right: The Mississippi Delta Hip-hop Story (Jackson, MS: University Press of Mississippi, 2009).

Petchauer, Emery, Hip-hop Culture in College Students' Lives: Elements, Embodiment, and Higher Edutainment (New York: Routledge, 2012).

Schloss, Joseph G., Making Beats: The Art of Sample-Based Hip-Hop (Middletown, CT: Wesleyan University Press, 2004).

Taylor, Paul C., "Does Hip Hop Belong to Me? The Philosophy of Race and Culture," in Derrick Darby and Tommie Shelby (eds.), Hip Hop and Philosophy: Rhyme 2 Reason (Chicago: Open Court Publishing, 2005), pp. 79-91.

\section{Notes}

1 Anthony Kwame Harrison, Hip Hop Underground: The Integrity and Ethics of Racial Identification (Philadelphia: Temple University Press, 2009).

2 Martyn Hammersley and Paul Atkinson, Ethnography: Principles in Practice, 2nd edn. (New York: Routledge, 1995), p. 1.

3 Will Hermes, "The World's Greatest Record Store?" Rolling Stone 780, February 19, 1998,

pp. 19-20.

4 The description of Northampton comes from Jason Rodriquez's ethnographic study of colorblind ideology among hip hoppers there: "Color-Blind Ideology and Cultural Appropriation in Hip-Hop," Journal of Contemporary Ethnography 35/6 (2006): 651.

5 Murs had released F'Real as an underground tape three years earlier.

6 Both this conversation with Murs and the conversation below with Lord Top Ramen were reconstructed from ethnographic fieldnotes written on April 26, 2000 and May 1, 2000 respectively.

7 Erving Goffman, The Presentation of Self in Everyday Life (Woodstock, NY: The Overlook Press, 1973 (1959]).
8 Harrison, Hip Hop Underground, p. 39.

9 The late Richard Peterson and Andy Bennett authored the definitive description of music scenes as "contexts in which clusters of producers, musicians, and fans collectively share their common musical tastes and collectively distinguish themselves from others."

"Introducing Music Scenes," in Andy Bennett and Richard Peterson (eds.), Music Scenes: Local, Translocal, Virtual (Nashville, TN: Vanderbilt University Press, 2004), p. 1. Of course, an aspect of this collectivity - of sharing and distinguishing - involves the co-performance and experience of "the social in the individual and the individual in the social." Simon Frith, "Music and Identity," in Stuart Hall and Paul du Gay (eds.), Questions of Cultural Identity (London: Sage Publication, 1996), p. 109.

10 "Impression management" refers to the strategic process through which social actors attempt to influence others' perceptions of them by avoiding "inadvertent acts" and "unmeant gestures" which may portray them in a less than flattering light. See Goffinan, The Presentation of Self, pp. 208-237. 
11 W. E. B. DuBois, The Souls of Black Folk

(New York: Penguin Books, 1996 [1903]), p. 4.

12 The concept of "microscene" - in reference to "a distinct component of a music scene located in a delimited space of mutual social activity, where certain clusters of scene members assemble and generate socio-cultural cohesion through collective ideologies, attitudes, preferences, practices, customs, and memories that distinguish them from the larger scene ${ }^{n}$ was developed in Geoff Harkness, "Gangs and Gangsta Rap in Chicago: A Microscenes Perspective," Poetics 41/2 (2013): 159. 13 "Thick description" is an interpretive approach to ethnographic analysis popularized by anthropologist Clifford Geertz. It involves densely textured depictions and explanations of social acts and activities, which strive to uncover the layers of cultural significance that underlie them. Clifford Geertz, The Interpretation of Cultures (New York: Basic Books, 1973), pp. 3-30. Norman K. Denzin defines autoethnography as "a turning of the ethnographic gaze inward on the self (auto), while maintaining the outward gaze of ethnography, looking at the larger context wherein self-experiences occur." Denzin, Interpretive Ethnography: Ethnographic Practice for the 21st Century (Thousand Oaks, CA: Sage, 1997), p. 227. Similarly, Tami Spry describes it as "a self-narrative that critiques the situatedness of self with others in social contexts" and "a vehicle of emancipation from cultural and familial identity scripts." Spry, "Performing Autoethnography: Embodied Methodological Praxis," Qualitative Inquiry 7/6 (2001): 710, 708. Whereas most contemporary ethnographies have autoethnographic dimensions to them, here I showcase these aspects in order to efficiently and effectively present the micro-social interactive dynamics I am theorizing.

14 Other disciplines that have embraced ethnography include education, geography, history, planning, political science, psychology, tourism and leisure studies, criminology, architecture, social work, and law. For an early commentary on the death and potential value of ethnography in popular music studies, see Sara Cohen, "Ethnography and Popular Music Studies," Popular Music 12/2 (1993): 123-138. 15 Bronislaw Malinowski, Argonauts of the Western Pacific (London: Routledge and Kegan Paul, 1966 [1922]), p. 25. Malinowski is generally regarded as the "founding father" of ethnography and many of the methodological precepts he introduced (or popularized) including participant-observation, learning the local language, and spending a minimum of one year in the field - are still widely observed among ethnographers today. Julie S. Jones, "Origins and Ancestors: A Brief History of Ethnography," in Julie S. Jones and Sal Watt (eds.), Ethnography in Social Science Practice (New York: Routledge, 2010), pp. 17-18. 16 For a discussion of close-to-home ethnography, see Mary Pattillo-McCoy, Black Picket Fences: Privilege and Peril among the Black Middle Class (University of Chicago Press, 1999), pp. 7-10.

17 The modification of behavior in response to being studied is commonly referred to as the "Hawthorne effect" - named after the factory in which a series of 1920 s and 1930 s workplace studies were conducted (for a critical commentary, see Stephen R. G. Jones, "Was There a Hawthorne effect?" American Journal of Sociology 98/3 (1992): 451-468). Through long-term residence, participation in daily life, and additional efforts to "fit in," anthropologists strive to minimize such behavior modifications. 18 For a comprehensive treatment of these developments, see Dennison Nash and Ronald Wintrob, "The Emergence of Self-Consciousness in Ethnography," Current Anthropology 13/5 (1972): 527-542; James Clifford, "Introduction: Partial Truths," in James Clifford and George E. Marcus (eds.), Writing Culture: The Poctics and Politics of Ethnography (Berkeley, CA: University of California Press, 1986), pp. 1-26; Diane L. Wolf, "Situating Feminist Dilemmas in Fieldwork," in Diane L. Wolf (ed.), Feminist Dilemmas in Fieldwork (Boulder, CO: Westview Press, 1996), pp. 1-55.

19 Peter McLaren, "Field Relations and the Discourse of the Other: Collaboration in Our Own Ruin," in William Shaffir and Robert A. Stebbins (eds.), Experiencing Fieldwork: An Insider View of Qualitative Research (Thousand Oaks, CA: Sage Publications, 1991), pp. 153-157. For an exemplary discussion of identity negotiations in ethnographic research, see Takeyuki Tsuda, "Ethnicity and the Anthropologist: Negotiating Identities in the Field," Anthropological Quarterly 71/3 (1998): $107-124$

20 Etienne Wenger, Communities of Practice: Learning, Meaning, and Identiry (Cambridge University Press, 1998).

21 Sarah Thornton argues that social class may not be as important to this sense of subcultural belonging, since subcultures tend to embrace a fantasized classlessness. Sarah Thornton, Club Cultures: Music, Media and Subcultural Capital (Cambridge: Polity, 1995), p. 12.

22 The definitive analysis of authenticity in hip-hop was conducted by Kembrew Mcleod, "Authenticity within Hip Hop and Other 
Cultures Threatened with Assimilation," Journal of Communication 49/4 (1999): 134-150.

23 Elsewhere, I have argued that the discourses surrounding underground hip-hop seek to disrupt dominant conceptions of hip-hop's racial and class-based identities while largely overlooking gender (see Harrison, Hip Hop Underground).

24 The first comprehensive global survey of hip-hop was Tony Mitchell (ed.), Global Noise: Rap and Hip Hop Outside the USA (Middletown, CT: Wesleyan University Press, 2001). The referenced ethnographic studies are Andy Bennett, "Rappin' on the Tyne: White Hip Hop Culture in Northeast England - an Ethnographic Study," Sociological Review 47/1 (1999): 1-24; lan Condry, Hip-Hop Japan: Rap and the Paths of Cultural Globalization (Durham, NC: Duke University Press, 2006); Sujatha Fernandes, Cuba Represent Cuban Arts, State Power, and the Making of New Revolutionary Cultures (Durham, NC: Duke University Press, 2006); Ayhan Kaya, "Sicher in Kreuzberg." Constructing Diasporas: Turkish Hip-hop Youth in Berlin (Bielefeld: Transcript, 2001); lan Maxwell, Phat Beats, Dope Rhymes: Hip Hop Down Under Comin' Upper (Middletown, CT: Wesleyan University Press, 2003).

25 Andreana Clay, The Hip-Hop Generation Fights Back: Youth, Activism, and Post-Civil Rights Politics (New York University Press, 2012); Ali Colleen Neff, Let the World Listen Right: The Mississippi Delta Hip-hop Story (Jackson, MS: University Press of Mississippi, 2009); Emery Petchauer, Hip-hop Culture in College Students' Lives: Elements, Embodiment, and Higher Edutainment (New York: Routledge, 2012); Joseph G. Schloss, Making Beats: The Art of Sample-Based Hip-Hop (Middletown, CT: Wesleyan University Press, 2004); Joseph G. Schloss, Foundation: B-Boys, B-Girls, and Hip-Hop Culture in New York (New York: Oxford University Press, 2009). I should also mention important ethnographic works by first-generation hip-hop scholars including: Cheryl L. Keyes, Rap Music and Street Consciousness: Music in American Life (Chicago: University of Illinois Press, 2004); Marcyliena Morgan, The Real Hiphop: Battling for Knowledge, Power, and Respect in the LA Underground (Durham, NC: Duke University Press, 2009).

26 I credit this notion of scholar-practitioner to a roundtable discussion I participated in with Neff, Schloss, Wang, and Fernandes at the 2012 EMP/IASPM - US branch joint conference in New York University. For a discussion of the virtues of ethnographic outsiderness when researching hip-hop, see Ian Maxwell, "The
Curse of Fandom: Insiders, Outsiders and Ethnography," in David Hesmondhalgh and Keith Negus (eds.), Popular Music Studies (London: Arnold, 2002), pp. 103-116.

27 This idea of what we ask of race comes out of Kwame Appiah's assertion that "There is nothing in the world that can do all we ask race to do for us." Appiah, In My Father's House: Africa in the Philosophy of Culture (New York: Oxford University Press, 1992), p. 45. 28 Harrison, Hip Hop Underground, pp. $139-140$.

29 The Day One open mic has an informal "pass the mic" format, in which emcees are usually expected to freestyle for about a minute and it's generally understood that everyone will take a turn before an $\mathrm{MC}$ goes again (see Harrison, Hip Hop Underground, p. 75). 30 At one point that summer, Top $\mathrm{R}$ recorded and sold a 90-minute (TDK) cassette tape of himself freestyling over various hip-hop instrumentals for five dollars a unit. See Anthony Kwame Harrison, "'Cheaper Than a CD, Plus We Really Mean It': Bay Area Underground Hip Hop Tapes as Subcultural Artefacts," Popular Music 25/2 (2006): 293. According to a local hip-hop retailer and close friend of Top R's, the underground freestyle tape took only a couple of hours to record. That same retailer approached me a few weeks later asking if he could borrow my copy in order to dub it. He had apparently sold out of Top R's freestyle tape and was looking to make more copies. 31 Oakland is affectionately called "the (Oak) Town," which is juxtaposed to "the (San Francisco) City."

32 For discussions of white appropriation of Black culture, see Margo lefferson, "Ripping off Black Music: From Thomas 'Daddy' Rice to Jimi Hendrix," Harpers, January (1973): 40-45; Perry A. Hall, "African-American Music: Dynamics of Appropriation and Innovation," in Bruce Ziff and Pratima V. Rao (eds.), Borrowed Power: Essays on Cultural Appropriation (New Brunswick, NJ: Rutgers University Press, 1997), pp. 31-51; Greg Tate, "Introduction: Nigs R Us, or How Blackfolk Became Fetish Objects," in Greg Tate (ed.) Everything but the Burden: What White People are Taking from Black Culture (New York: Broadway Books, 2003), pp. 1-14. For commentaries on white hip-hoppers' position in this dynamic, see Nelson George, Hip Hop America (New York: Viking Press, 1998); Paul C. Taylor, "Does Hip Hop Belong to Me? The Philosophy of Race and Culture," in Derrick Darby and Tommie Shelby (eds.), Hip Hop and Philosophy: Rhyme 2 Reason (Chicago: Open Court Publishing, 2005), pp. 79-91. 
33 According to the then-most-recent (2000) census, the Bay Area population was 50 percent white, 7 percent Black, 19 percent Hispanic, and 19 percent Asian/Pacific-Islander, with just over 3 percent of people identifying as "two or more races." Of course, these numbers vary with regards to specific Bay Area cities and districts (see Harrison, Hip Hop Underground.

pp. 18-21).

34 For critical commentaries on anthropology's sordid history, see Bernard Magubane and James C. Faris, "On the Political Relevance of Anthropology," Dialectical Anthropology 9/1-4 (1985): 91-104; Faye V. Harrison, Decolonizing Anthropology: Moving Further Towards an Anthropology for Liberation, third revision (Washington, DC: American Anthropological Association, 1997 [1991]).

35 For a discussion of the importance of being there in anthropology, see Clifford Geertz, Works and Lives: The Anthropologist as Author (Stanford University Press, 1988), pp. 1-24. 36 Lee offers the most comparable accounting of ethnographic immersion into a hip-hop open microphone (micro)scene. See Jooyoung Lee, "Open Mic: Professionalizing the Rap Career," Ethnography 10/4 (2009): 479-483. Although Morgan immersed herself in the same (Project Blowed) open mic scene as Lee, she offers little to no description of her direct experiences aside from saying that she was "constantly tested and challenged" (The Real Hiphop, p. 15). While my discussion in this chapter focuses on race, I think it is worth considering the extent to which gender impacted Morgan's (less-disclosed) experiences as an African American woman.

37 Lee was a Korean American conducting research within a predominantly African American Los Angeles open-microphone scene ("Open Mic," pp. 479-481).

38 Ecko Unltd. is a brand of urban apparel often associated with hip-hop.

$39 \mathrm{My}$ understanding of norms of identification is developed from Kwame A. Appiah, "Does Truth Matter to Identity?," in Jorge J. E. Garcia (ed.), Race or Ethnicity? On Black and Latino Identity (Ithaca, NY: Cornell University Press, 2007), pp. 29-30.

40 Top R and Murs were certainly friends. In fact, later that year when Murs released his Murs Rules the World CD, one of the songs ("Way Tight") included a "What's up to... Top R." 41 DuBois, The Souls of Black Folk.

42 Appiah, "Does Truth Matter to Identity?," p. 21.

43 Ibid., p. 27.

44 Of course, where Black and white have historically been the most tightly bound racial classifications in American society, people identifying broadly as Latino or Asian/PacificIslander are more inclined to identify as members of ethno-racial, or simply ethnic, groups such as Puerto Rican, Filipino, or Mexican.

45 John L. Jackson, Jr., Real Black: Adventures of Racial Sincerity (University of Chicago Press, 2005), p. 13; for a thoughtful discussion of racial sincerity in hip-hop, see ibid., pp. 173-196. 46 Appiah, "Does Truth Matter to Identity?," p. 28.

47 See Harrison (ed.), Decolonizing

Anthropology.

48 When William "Upski" Wimsatt published his exposé of white rappers in the May 1993 issue of The Source, it immediately became "the most responded to article in the history of hip hop journalism." William U. Wimsatt, Bomb the Suburbs, 2 nd edn. (Chicago: The Subway and Elevated Press Company, 1994), p. 22. Ten years later, The Source would publish a scathing critique of Eminem authored by Public Enemy Media Assassin Harry Allen ("The Unbearable Whiteness of Emceeing: What the Eminence of Eminem Says About Race," The Source, February [2003]: 91-92). I would add, quite simply, that the mere mention of Vanilla Ice's name continues to be a punchline in most contexts where I've seen the white rapper brought up. 49 This episode is recounted in the opening pages of Harrison, Hip Hop Underground, pp. $1-4$. 
The Cambridge Companion to HIP-HOP

EDITED BY

Justin A. Williams 